\title{
Yoga management of breast cancer-related lymphoedema: a randomised controlled pilot-trial
}

\author{
Annette Loudon', Tony Barnett ${ }^{1}$, Neil Piller ${ }^{2}$, Maarten A Immink ${ }^{3}$ and Andrew D Williams ${ }^{4^{*}}$
}

\begin{abstract}
Background: Secondary arm lymphoedema continues to affect at least 20\% of women after treatment for breast cancer requiring lifelong professional treatment and self-management. The holistic practice of yoga may offer benefits as an adjunct self-management option. The aim of this small pilot trial was to gain preliminary data to determine the effect of yoga on women with stage one breast cancer-related lymphoedema (BCRL). This paper reports the results for the primary and secondary outcomes.
\end{abstract}

Methods: Participants were randomised, after baseline testing, to receive either an 8-week yoga intervention ( $n=15)$, consisting of a weekly 90-minute teacher-led class and a 40-minute daily session delivered by DVD, or to a usual care wait-listed control group $(n=13)$. Primary outcome measures were: arm volume of lymphoedema measured by circumference and extra-cellular fluid measured by bioimpedance spectroscopy. Secondary outcome measures were: tissue induration measured by tonometry; levels of sensations, pain, fatigue, and their limiting effects all measured by a visual analogue scale (VAS) and quality of life based on the Lymphoedema Quality of Life Tool (LYMQOL). Measurements were conducted at baseline, week 8 (post-intervention) and week 12 (four weeks after cessation of the intervention).

Results: At week 8, the intervention group had a greater decrease in tissue induration of the affected upper arm compared to the control group $(p=0.050)$, as well as a greater reduction in the symptom sub-scale for $Q O L(p=0.038)$. There was no difference in arm volume of lymphoedema or extra-cellular fluid between groups at week 8; however, at week 12, arm volume increased more for the intervention group than the control group ( $p=0.032)$.

Conclusions: An 8-week yoga intervention reduced tissue induration of the affected upper arm and decreased the $\mathrm{QOL}$ sub-scale of symptoms. Arm volume of lymphoedema and extra-cellular fluid did not increase. These benefits did not last on cessation of the intervention when arm volume of lymphoedema increased. Further research trials with a longer duration, higher levels of lymphoedema and larger numbers are warranted before definitive conclusions can be made.

Keywords: Yoga, Breast cancer-related lymphoedema, Symptoms, Quality of life, Randomised controlled trial

\section{Background}

Breast cancer is the second most common form of cancer in women after skin cancer, and its incidence is expected to rise due to the ageing population [1]. In spite of improvements to surgical and radiotherapy treatment, at least $20 \%$ of treated women will continue to be diagnosed with breast cancer-related lymphoedema (BCRL) [2] that requires lifelong treatment and management [3].

\footnotetext{
* Correspondence: Andrew.Williams@utas.edu.au

${ }^{4}$ School of Health Sciences, University of Tasmania, Launceston, Australia Full list of author information is available at the end of the article
}

As well as fibrosis of the tissue and increased risk of infection [4], women with BCRL can experience a range of debilitating sensations and symptoms $[5,6]$ and in comparison to women who have had breast cancer treatment without lymphoedema, have impaired physical function [7] and lower quality of life (QOL) [8].

Due to the multi-dimensional consequences of BCRL, a holistic management approach, including exercise, is recommended [3]. Previously, exercise participation was discouraged due to concerns that exercise may exacerbate the condition; however, there is growing evidence to support the use of progressive and supervised exercise

\section{() Biomed Central}

(c) 2014 Loudon et al.; licensee BioMed Central Ltd. This is an Open Access article distributed under the terms of the Creative Commons Attribution License (http://creativecommons.org/licenses/by/2.0), which permits unrestricted use, distribution, and reproduction in any medium, provided the original work is properly credited. 
for women with BCRL with adequate warm-up, cool-down, appropriate rests [9] and suitable training of staff [10]. This evidence comes from studies covering a range of exercise modalities, which have reported no increase in severity $[11,12]$ and fewer exacerbations of lymphoedema [13], increased strength [13], reductions in symptoms [13,14], and improvements in QOL $[15,16]$. In light of this, research into other holistic interventions, including yoga, for women with BCRL has been recommended $[6,9,14]$. Yoga is a holistic system of practices that aims to create balance in the physical, mental and emotional self [17]. It includes breathing (pranayama), postures (asana), meditation and relaxation. The physical movements and slow breathing, which can be adapted to principles of lymphatic clearing, have been used effectively as part of a holistic treatment to reduce lower limb lymphoedema from filariasis [18]. The practices of breathing, meditation and relaxation have been reported to improve the psychosocial functioning of women during and after breast cancer treatment [19]. These outcomes may be transferrable to women with BCRL. Women with BCRL are already attending yoga sessions [20], though the outcomes from this have not been systematically investigated.

The aim of this study was to obtain preliminary data to determine the effect of yoga on women with BCRL. This paper reports the results of the primary outcomes of lymphoedema status and the secondary outcomes of lymphoedema symptoms and QOL in women with stage one BCRL. We hypothesised that yoga would reduce swelling caused by lymphoedema relative to usual care and would lead to a reduction in tissue induration and severity of sensations, pain and fatigue associated with lymphoedema and their limiting effects, and improve QOL.

\section{Methods}

\section{Study design}

The trial was a multi-centred randomised controlled pilot trial using a parallel design with participants allocated to intervention or control on a 1:1 allocation ratio. The study was registered with the Australian New Zealand Clinical Trials Registry and ethics approval was granted by the University of Tasmania's Social Sciences Human Research Ethics Committee. This study was part of a larger mixed methods study. The full protocol has been described previously [21]. This paper presents the results for the primary outcomes of arm volume of lymphoedema and extra-cellular fluid and the secondary outcomes of tissue induration, sensations and their limiting effects and QOL.

After meeting the selection criteria and giving informed consent, participants were randomised to a yoga intervention group or a wait-listed usual care control group. Outcome measurements were performed at baseline (week 0), week 8 (on completion of intervention) and at week 12 (one month after intervention). All intervention and data collection sessions were held in Community Health Centres at two locations, Hobart and Launceston, between February and May 2011. Both locations consisted of an intervention and control group.

Randomisation was conducted by a person not associated with the trial from a computer-generated random number system (http://www.randomization.com). No stratification occurred. Participants received notification of their group allocation in sealed envelopes after baseline testing.

\section{Participants \\ Eligibility criteria}

Women were eligible for inclusion if they had stage one unilateral secondary lymphoedema of the arm, as defined by the International Society of Lymphology [3] confirmed by a professional lymphoedema therapist, and had completed treatment for breast cancer (surgery, radiotherapy and chemotherapy) at least six months previously, were over 18 and had sufficient English literacy to provide informed consent. Briefly, stage one lymphoedema is defined as early stage lymphoedema that will subside with elevation and may have signs of pitting and was chosen for this trial for two principal reasons. Firstly, as this was the first 8-week pilot trial to use a yoga intervention, women's safety was paramount and it was thought that lower levels of lymphoedema may be more stable during the intervention period. Secondly, the standard offers a definition that could be confirmed or negated by a qualified lymphoedema therapist to account for different methods of clinical measurement. Measurement of women to confirm lymphoedema status was not possible prior to baseline testing because non-metric measurement equipment was not available to clinicians.

Women were excluded if they had recurrent cancer, an infection, were having Complex Lymphoedema Therapy, if they were pregnant, wore a pacemaker, which would affect bioimpedance spectroscopy (BIS) readings, or had severe psychological illness. All participants in the trial received a manual containing information on best current care for BCRL. Women were advised not to change current exercise nor commence any new activity during the study period and to seek immediate medical help if they experienced an exacerbation of lymphoedema during the trial.

\section{Control group}

Participants randomised to the control group maintained their usual self-care as advised by their lymphoedema therapist. Self-care included wearing of compression sleeves, self-massage, skin protection and continued usual lymphatic treatment. The control group were offered yoga classes at the completion of the final measurement. 


\section{Yoga intervention group}

Participants randomised to the intervention group attended a weekly 90-minute yoga class taught by an experienced and accredited yoga teacher with qualifications in yoga therapy and Manual Lymphatic Drainage. Participants were also given a DVD with a 45-minute yoga session and instructed to perform it daily. The DVD followed the same sequence of practices as the class, with fewer postures and a shorter relaxation. Participants received a logbook in which they recorded their daily practice along with any relevant comments. Women were given the choice to wear a compression sleeve and, if removed, instructed to wear it again immediately after the yoga session [22].

The yoga session included documented breathing practices, physical postures, meditation and relaxation techniques according to the Satyananda Yoga ${ }^{\oplus}$ tradition [23] (Table 1). This style offers systematised practices and instruction thought to be suited to women with BCRL. Options for modifications were offered in the class and DVD. The practices were chosen to promote lymphatic drainage and to reduce stress and conformed with exercise guidelines and precautions for women with BCRL [3,9]. A full rationale for the session and chosen practices has been provided previously [24].

\section{Outcome measures}

Measurements, based on validated instruments and protocols, were taken by trained researchers blinded to the group allocation and previous results. Severity of lymphoedema for arm volume and extra-cellular fluid and tissue induration were measured by an experienced and registered lymphoedema physiotherapist at each location. Inter-rater reliability between lymphoedema therapists was assessed pre-trial and rated as acceptable for variability's between 2-3\%. Other trained assessors administered anthropometric measurements and questionnaires at both places on different days. To ensure consistency at each time-point, participants attended at the same time throughout the trial and the same assessor was responsible for each measure. Participants were requested to abstain from alcohol for 12 hours and caffeine and exercise for two hours before testing to increase the validity of the BIS readings.

On arrival at the testing facility, participants underwent anthropometric measurements wearing light clothes and no footwear. Participants then underwent measures of lymphoedema and tissue induration and completed VAS and QOL questionnaires in the same order at each measurement session.

\section{Lymphoedema}

Lymphoedema was measured with the participant supine and arm dominance noted. Women removed their sleeve on entering the measurement venue. Two measures were chosen: arm volume from circumference and extra-cellular fluid from BIS. These measures can give different outcomes $[25,26]$; for example, BIS results include the fluid in the upper part of the arm where it is difficult to get circumferential readings.

Circumferential readings were taken by a Jobst nonstretch tape according to an established protocol [27] at the metacarpophalangeal joint and at $10 \mathrm{~cm}$ intervals from the styloid process. Volume of arm lymphoedema was calculated using the truncated cone formula [28] from the addition of circumferential readings using an Excel spreadsheet that compared the affected to the non-affected arm, resulting in a measure of Absolute Arm Volume between the affected and non-affected arm. Measurements were recorded in millilitres $(\mathrm{ml})$.

Extra-cellular fluid was measured by BIS L-dex XCA ${ }^{\mathrm{mm}}$ (Bio-Impedimed, Queensland) [29]. Electrodes were placed at anatomical landmarks at the wrist of each arm and right ankle to provide a low-frequency electrical current. An increase in extra-cellular fluid is paralleled by a decrease in impedance and the result recorded as a ratio to the nonaffected arm, taking into consideration arm dominance [26]. The result was an L-dex reading, calculated from software provided by the manufacturer.

\section{Tissue induration}

Induration of fibrotic tissue was measured using a digital tonometer, model 1383 (Biomedical Engineering, Flinders Medical Centre, South Australia) [30]. The digital tonometer measures the resistance to compression in the superficial tissues at a given point on the areas of lymph drainage (lymphatic territory) [25]. Measurements were taken $10 \mathrm{~cm}$ from the cubital fossa on the forearm and $10 \mathrm{~cm}$ from the cubital fossa on the upper arm, in the middle of the areas of lymphatic territory. Anterior trunk measurements were taken at the mid-clavicular line between the second and third ribs and at the posterior trunk between the acromion and the first thoracic rib in the subscapular fossa. Measurements were taken three times at each position, separated by a three-second pause, for the affected and non-affected arm and trunk. A higher score denoted a higher level of induration of fibrotic tissue. The average of three measurements was recorded in millimetres $(\mathrm{mm})$.

\section{Sensations, pain and fatigue and their limiting effects}

Participants recorded the severity of sensations, pain and fatigue, and the degree to which sensations, pain and fatigue limited activity on the day of measurement on a $10 \mathrm{~cm}$ Visual Analogue Scale (VAS) [31]. A score of $0 \mathrm{~cm}$ indicated "no discomfort" and a score of $10 \mathrm{~cm}$ indicated "the worst imaginable".

\section{Quality of life}

A validated questionnaire, developed specifically to measure QOL for people with arm lymphoedema, LYMQOL 
Table 1 Yoga session weeks 1-8 including on DVD

\begin{tabular}{|c|c|}
\hline Practice and time allocated & Sanskrit \\
\hline \multicolumn{2}{|c|}{ Settling and Breathing 10 minutes (DVD 10 minutes) } \\
\hline Settling with awareness ${ }^{*}$ & Kaya Sthairyam [1] \\
\hline Mindfulness (inner silence) ${ }^{*}$ & Antar Mouna level one [2] \\
\hline Abdominal, thoracic, clavicular breath ${ }^{*}$ & Pranayama [3] \\
\hline Full yoga breath ${ }^{*}$ & Pranayama [3] \\
\hline \multicolumn{2}{|l|}{ Postures 35 minutes (DVD 25 minutes) [3] } \\
\hline 1a Neck turns ${ }^{*}$ & Greeva Sanchalana \\
\hline 1b Add outward rotation of opposite $\mathrm{arm}^{*}$ & Utthanpadasana-variation \\
\hline 3 Knee hugs-leg lock pose ${ }^{*}$ & Supta Pawanmuktasana \\
\hline 4 Shoulder circles ${ }^{*}$ & Shandha Chakra \\
\hline 5 Bent arm opening, chest towards knees ${ }^{*}$ & Naukasana-variation combined with Namaskarasana-variation of arms \\
\hline 6 Lying Archer & Akarna Dhanurasana-variation \\
\hline 7 Lying rotation ${ }^{*}$ & Supta Udarakarshanasana-variation \\
\hline 8 Arm/leg stretch ${ }^{*}$ & Supta Pawanmuktasana \\
\hline 9 Sitting rowing ${ }^{*}$ & Nauka Sanchalanasana \\
\hline 10 Standing archer ${ }^{*}$ & Akarna Dhanurasana \\
\hline 11 Modified rope climbing ${ }^{*}$ & Rajju Karshanasana-variation \\
\hline 12 Modified arm raise, knee bend ${ }^{*}$ & Tadasana-variation \\
\hline 13 Modified side bend ${ }^{*}$ & Trikonasana-variation \\
\hline 14 Standing rotation ${ }^{*}$ & Kati Chakrasana \\
\hline 15 Standing Cat ${ }^{*}$ & Marjari-asana_variation \\
\hline 16 Modified one legged prayer balance & Eka Pada Pranamasana \\
\hline 17 Sitting neck turns ${ }^{*}$ & Greeva Sanchalana \\
\hline \multicolumn{2}{|l|}{ Mindfulness, Pranayama, Meditation 10 minutes } \\
\hline Settling with awareness and stillness & Kaya Sthairyam \\
\hline \multirow[t]{2}{*}{ "Mindfulness practice (inner silence) } & Antar Mouna level one Weeks 1-4 \\
\hline & Antar Mouna level one Weeks 5-8 \\
\hline Alternate nostril breathing & Nadi Shodan [3] \\
\hline *Visualisation One-pointed focus-lymph system & Dharana [2] \\
\hline Meditation One-pointed focus candle & Tratak [3] Weeks 7 and 8 \\
\hline \multicolumn{2}{|c|}{ Relaxation-meditation 20 minutes (DVD 10 minutes) } \\
\hline *Deep relaxation & Yoga Nidra [4] \\
\hline
\end{tabular}

\section{*Practice in DVD.}

Full description of each practice:

1. Saraswati, N., Dharana Darshan-Yogic, Tantric and Upanishadic Practices of Concentratrionand Visualization. 2003. Yoga Publications Trust, Munger, Bihar,

India. 439.

2. Saraswati, S. Meditations from the Tantras. 2001. Yoga Publications Trust, Munger, Bihar, India. 367.

3. Saraswati, S. Asana, Pranayama, Mudra, Bandha. 1996, Munger, India: Bihar School of Yoga. 543.

4. Saraswati, S. Yoga Nidra. 6th ed. 2006, Munger, India: Bihar School of Yoga. 261.

[32], was used. Total QOL was self-recorded with scores from $0-10$, ten being the best and zero the worst rating on the day of testing. Sub-scales, each consisting of several questions, for function, symptoms, appearance and emotions, were also self-recorded. Each question was scaled from 1 to 4 , four being the worst. The score for each subscale was based on the mean of the ratings for sub-scale related questions. A higher score indicated a lower QOL rating for that sub-scale.

\section{Data analysis}

An a priori sample size calculation was performed and indicated that 19 participants per group would be required to detect statistically significant changes in the primary 
outcome variables. As the number of participants was limited by time and other practical constraints, a pilot study was conducted.

Baseline information between treatment groups for demographic and medical characteristics were compared by independent two-tailed t-tests for continuous variables and by Yates corrected chi-square tests for categorical variables (SPSS version 19; IBM, Armonk, New York, USA). Statistical analyses of outcome measures at baseline and changes between groups at weeks 8 and 12 were performed using STATA statistical software (version 12; STATA Corporation, College Station, Texas, USA). Parametric longitudinal data were analysed via mixed methods linear regression (ANOVA). Where assumptions of linear regression were violated, data were analysed using nonparametric analysis via ordinal logistic regression. In both methods of analysis, the independent variables were time and group while the dependent variables included lymphoedema (L-Dex, arm volume), tissue induration, sensations and quality of life. Post-hoc testing was performed on all data using the Holms test to locate the means that were significantly different. Statistical significance was set at $\mathrm{p}<0.05$. Due to the low sample size neither multivariate nor covariate analyses were performed. Data is presented as Mean and Standard Deviation unless otherwise indicated.

\section{Results}

\section{Participant flow and compliance}

The flow of participants through the trial is outlined in Figure 1. Participants in the study were asked at each assessment point whether they had experienced any adverse events (pain or abnormal sensation) that might be associated with the intervention. There were no adverse events attributable to either the yoga or the control intervention. Two participants withdrew after being diagnosed with recurrent cancer during the trial while five others experienced adverse events requiring their withdrawal from the study that were unrelated to either their condition or the treatment. Details of these adverse events are included in Figure 1.

Due to attrition, fewer participants returned for the week-12 follow-up than completed the week 8 measurements. Consequently, the results from baseline to end of the 8 week intervention (b-8) and end of the week 8 intervention to week 12 follow up (8b-12) were analysed separately. Attendance at the group yoga sessions was high (97\%), as was self-reported compliance with the home-practice DVD (86\%).

\section{Baseline demographics and medical characteristics}

Twenty-three participants, with a mean age of $57.6 \pm$ 10.5 years (range 34-80) and a mean BMI of $27.2 \pm 4.9 \mathrm{~kg} /$ $\mathrm{m}^{2}$ (range 20.4-37.3), completed the eight week intervention and 19 women returned for the week 12 follow up measurement. No women in either group were doing yoga, apart from that prescribed for the intervention group, during the trial, nor had they done it since developing BCRL.

At baseline, the intervention group had a significantly higher BMI $\left(29.1 \mathrm{~kg} / \mathrm{m}^{2} \pm 4.6 ; \mathrm{p}=0.023\right)$ than the control group $\left(25.1 \mathrm{~kg} / \mathrm{m}^{2} \pm 4.5\right)$. There were no other significant differences between the intervention and control groups in demographics or medical characteristics at baseline (Table 2).

\section{Outcomes \\ Lymphoedema status}

All participants had been clinically diagnosed with lymphoedema by professional and experienced lymphoedema therapists. We used two methods of measure to determine changes in lymphoedema in the trial due to the variance that can occur in the definition of lymphoedema and to quantify changes that could occur from the intervention. At some measurements some women in both groups may have had variation in lymphoedema status. As this was a controlled trial we did not account for fluctuation.

\section{Volume of arm lymphoedema}

There was no between group difference in volume of arm lymphoedema measured by circumference at baseline. From b-8, there was no significant change between groups (Table 3 ).

From 8b-12 (Table 3), there was a significant change between groups in volume of arm lymphoedema ( $\mathrm{p}=$ $0.032)$ due to the significant increase in the intervention group (25.72 $\mathrm{ml}$; 95\% CI: 3.01 to $48.42 ; \mathrm{p}=0.026$ ).

\section{Extra-cellular fluid}

There was no between group difference in extra-cellular fluid measured by BIS at baseline. From b- 8 and $8 b-12$ there were no significant changes between groups (Table 3 ). Therefore, this pilot trial was negative with respect to the pre-specified primary outcomes.

\section{Tissue induration}

There were no between group differences for any measure of tissue induration of the affected or non-affected area measured by tonometry at baseline. From b-8, there was a significant decrease in tissue induration of the affected upper arm in the intervention compared to the control group $(\mathrm{p}=0.050)$ (Table 3$)$. From $8 \mathrm{~b}-12$, there were no significant changes in tissue induration between groups.

Degree of sensations, pain, fatigue and their limiting effects There were no between group differences for degree of sensations, pain, fatigue and their limiting effects measured by the VAS scale at baseline nor from b- 8 or $8 b-12$ (Table 4). 


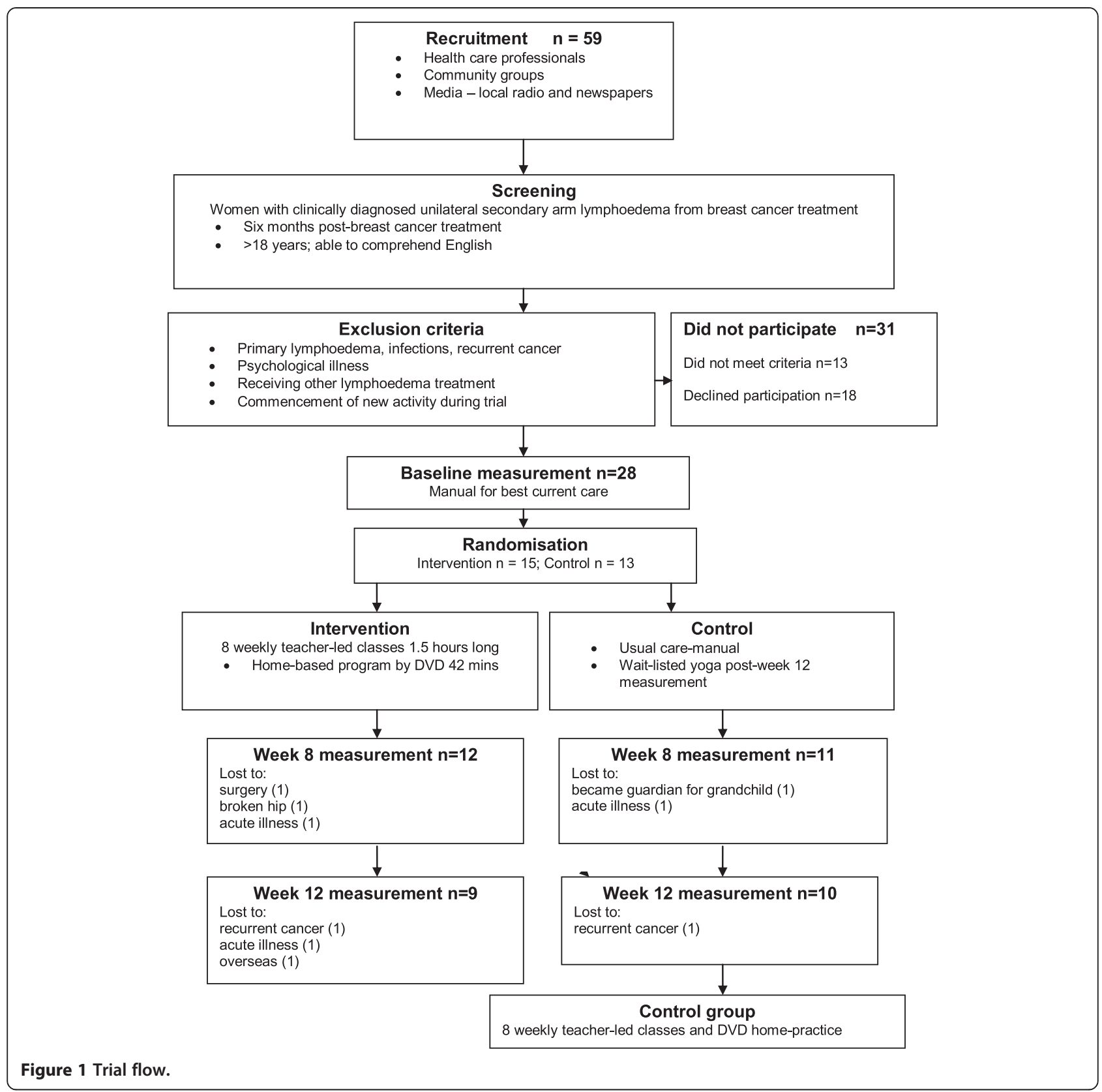

\section{Quality of life}

There were no between group differences for the subscales and total QOL score measured by LYMQOL at baseline. From b-8, there was a significant decrease (improvement) in the intervention compared to the control group in the QOL sub-scale of symptoms $\mathrm{p}=0.038$ ) (Table 5). From 8b-12, there were no significant changes between groups (Table 5).

\section{Discussion}

The aim of this small pilot trial was to gain preliminary evidence on the effects of an 8-week yoga intervention on women with stage one BCRL. This paper reports the results of the primary and secondary outcomes. The swelling caused by lymphoedema did not decrease. Eight weeks of yoga resulted in reductions in tissue induration of the affected upper arm and in the QOL sub-scale of symptoms specific to lymphoedema. However, these improvements were not sustained at one month post-intervention when arm volume of lymphoedema increased.

Severity of lymphoedema did not decrease and is comparable to the response from exercise interventions of varying durations and modalities for women with BCRL $[12,13,15]$. In the current study, L-dex readings from BIS were virtually unchanged and consistent with those of a 12-week combined aerobic and resistance intervention 
Table 2 Baseline demographics and medical characteristics of the groups

\begin{tabular}{llll}
\hline Characteristics & $\begin{array}{l}\text { Intervention } \\
(\mathbf{n = 1 2}) \\
\text { Mean } \pm \text { SD }\end{array}$ & $\begin{array}{l}\text { Cotnrol } \\
(\mathbf{n = 1 1 )} \\
\text { Mean } \pm \text { SD }\end{array}$ & P value $^{\mathbf{a}}$ \\
\hline Age (years) & $55.1 \pm 2.5$ & $60.5 \pm 3.6$ & 0.230 \\
BMI $\left(\mathrm{kg} / \mathrm{m}^{2}\right)$ & $29.1 \pm 4.6$ & $25.1 \pm 4.5$ & 0.023 \\
Range & $36-65$ & $34-80$ & \\
Number nodes removed & $14.3 \pm 2.3$ & $11.2 \pm 2.7$ & 0.429 \\
Number of positive nodes & $1.5 \pm 0.5$ & $3.7 \pm 2.3$ & 0.321 \\
How long lymphoedema (years) & $4.9 \pm 1.6$ & $5.1 \pm 1.9$ & 0.900 \\
How long post-surgery & $1.2 \pm 0.4$ & $1.9 \pm 0.7$ & 0.822 \\
& $\mathbf{n}(\%)$ & $\mathbf{n}(\%)$ & $\mathbf{P ~ v a l u e ~}^{\mathbf{b}}$
\end{tabular}

Living arrangements

\begin{tabular}{|c|c|c|c|}
\hline Live alone & $2(14)$ & $3(27)$ & 0.912 \\
\hline Live with others & $10(83)$ & $8(73)$ & \\
\hline \multicolumn{4}{|l|}{ Employment } \\
\hline Home, retired & $5(42)$ & $8(73)$ & 0.280 \\
\hline Employed & $7(58)$ & $3(27)$ & \\
\hline \multicolumn{4}{|l|}{ Fitness (self-scored) } \\
\hline Low & $2(17)$ & $1(9)$ & \\
\hline Medium & $8(67)$ & $8(73)$ & 0.913 \\
\hline High & $2(17)$ & $2(18)$ & \\
\hline \multicolumn{4}{|l|}{ Breast cancer surgery } \\
\hline Lumpectomy & $5(42)$ & $3(27)$ & 0.882 \\
\hline Mastectomy & $7(58)$ & $8(73)$ & \\
\hline \multicolumn{4}{|l|}{ Type of lymph dissection } \\
\hline Sentinel node & 0 & $1(9)$ & 0.980 \\
\hline Axillary clearance & $12(100)$ & 10(91) & \\
\hline \multicolumn{4}{|l|}{ Stage of breast cancer } \\
\hline DCIS & 0 & $1(9)$ & 0.976 \\
\hline 1 & $3(25)$ & $4(36)$ & \\
\hline 2 & $6(50)$ & $5(45)$ & \\
\hline 3 & $3(25)$ & $1(9)$ & \\
\hline \multicolumn{4}{|l|}{ Treatment and effects } \\
\hline Chemotherapy & $8(66)$ & $6(54)$ & 0.867 \\
\hline Effects chemotherapy & $7(58)$ & $4(36)$ & 0.525 \\
\hline Radiotherapy & $9(75)$ & $7(64)$ & 0.890 \\
\hline Effects radiotherapy & $8(67)$ & $3(27)$ & 0.198 \\
\hline \multicolumn{4}{|l|}{$\begin{array}{l}\text { Most common area } \\
\text { of radiotherapy }\end{array}$} \\
\hline Chest & $7(58)$ & $7(64)$ & 0.909 \\
\hline Axilla & $2(17)$ & $2(18)$ & \\
\hline Axilla and chest & $3(25)$ & $2(18)$ & \\
\hline \multicolumn{4}{|l|}{ Other post-surgery effetcs } \\
\hline Post-surgery infection & $3(25)$ & $3(27)$ & 0.725 \\
\hline Post-surgery cording & $3(25)$ & $3(27)$ & 0.725 \\
\hline Post-surgery fluid removal & $9(75)$ & $9(82)$ & 0.913 \\
\hline
\end{tabular}

[11], many of whose participants had low levels of lymphoedema, as in the current trial. In comparison to the BIS results, a significant decrease in volume of arm lymphoedema was recorded at week 8 in the intervention group. While it is possible this result may have been affected by a non-significant higher mean arm volume in the yoga group at baseline (Table 3 ), the result is consistent with the volume reduction $(\mathrm{p}=0.07)$ found after a four-week daily tai-chi and breathing intervention [14]. In addition, in our study this result was reversed at the week 12 follow-up. These results suggest that yoga may be beneficial in reducing or at least not increasing volume of arm lymphoedema in women with early-stage BCRL but needs to be ongoing as the benefits may disappear when yoga ceases.

The reduction in tissue induration of the affected upper arm in the intervention group compared to the control was a significant beneficial outcome of this trial. The yoga intervention focussed on the repetition and coordination of physical movements based on range of motion of the shoulders, spine and whole body, leading to a gentle, rhythmic stretching and compression of the skin and underlying tissue, particularly in the arms, chest and upper back. Researchers in a tai-chi trial that used a gentle arm opening and closing exercise for women with BCRL and reported a significant reduction in the tissue induration of the chest $(p=0.005)$ [14] suggested that those actions may have reduced adhesions caused by fibrosis and improved the quality of the underlying connective tissue. Both the current and the tai-chi trial combined slow physical movement with slow and controlled breathing, which also may have created a gentle stretching of the connective tissue of the secondary muscles of breathing, such as the pectoral and serratus anterior muscles, perhaps softening the tissue and enabling less restriction of shoulder movement. As stage one lymphoedema may not be accompanied by actual fibrotic tissue [3] we are unable to confirm its use in reducing fibrotic tissue. However, as fibrosis of tissue is a debilitating effect of lymphoedema and can increase the possibility of infection, the outcomes from the tai-chi and the current trial offer preliminary evidence of the beneficial effects of tai-chi and yoga in softening tissue that warrant further research.

The yoga session offered in this trial consisted not only of physical practices with focussed awareness on the breath and body, but also specific practices of breathing, relaxation and meditation, which are considered effective in improving biopsychosocial functioning [33]. The reduction in the LYMQOL sub-scale of symptoms at the completion of the yoga intervention is perhaps indicative of the holistic beneficial effects of yoga. Symptoms of lymphoedema adversely affect physical function and QOL in women with BCRL [8,34]. A qualitative study into the effect of 
Table 3 Results lymphoedema and tissue induration

\begin{tabular}{|c|c|c|c|c|c|c|c|c|c|}
\hline & \multicolumn{2}{|c|}{ Group mean \pm SD b-8 } & \multirow{2}{*}{$\begin{array}{l}\text { Between group changes 0-8 } \\
\Delta \text { int- } \Delta \text { con 0-8 MD; }(95 \% \mathrm{Cl})\end{array}$} & \multirow[b]{2}{*}{$P(0-8)$} & \multirow[b]{2}{*}{ Variable $\mathrm{Gp}(\mathrm{n})$} & \multicolumn{2}{|c|}{ Group mean \pm SD $8 b-12$} & \multirow{2}{*}{$\begin{array}{l}\text { Between group changes 8b-12 } \\
\Delta \text { int- } \Delta \text { con } 8 \mathrm{~b}-12 \mathrm{MD} ;(95 \% \mathrm{Cl})\end{array}$} & \multirow[b]{2}{*}{$P(8 b-12)$} \\
\hline Variable $G p(n)$ & Week $0 \mathrm{M} \pm \mathrm{SD}$ & Week $8 \mathrm{M} \pm \mathrm{SD}$ & & & & Week 8b M $\pm S D$ & Week $12 \mathrm{~m} \pm \mathrm{SD}$ & & \\
\hline \multicolumn{10}{|c|}{ Lymphoedema L-dex (BIS) } \\
\hline Con (11) & $6.49 \pm 14.14$ & $7.66 \pm 12.64$ & $-1.03 ;(-4.17$ to 2.10$)$ & 0.519 & Con(10) & $8.68 \pm 12.83$ & $7.83 \pm 13.59$ & $2.57 ;(-1.04$ to 6.18$)$ & 0.163 \\
\hline $\operatorname{lnt}(12)$ & $5.89 \pm 9.07$ & $6.03 \pm 8.24$ & & & $\operatorname{lnt}(9)$ & $4.96 \pm 6.40$ & $6.67 \pm 7.08$ & & \\
\hline \multicolumn{10}{|l|}{ Arm volume } \\
\hline Con(11) & $59.89 \pm 78.53$ & $60.75 \pm 80.69$ & $-30.28 ;(-69.33$ to 8.78$)$ & 0.129 & $\operatorname{Con}(10)$ & $67.65 \pm 82.39$ & $58.17 \pm 100.42$ & $35.20 ;$ (3.09 to 67.32$)$ & 0.032 \\
\hline $\operatorname{lnt}(12)$ & $101.45 \pm 75.08$ & $72.03 \pm 80.77$ & & & $\operatorname{lnt}(9)$ & $60.82 \pm 82.84$ & $86.53 \pm 78.29$ & & \\
\hline \multicolumn{10}{|c|}{ Tissue induration (Tonometry) Forearm affected } \\
\hline Con(11) & $13.96 \pm 3.82$ & $14.06 \pm 4.80$ & $0-1.89 ;(-4.88$ to 1.16$)$ & 0.227 & $\operatorname{Con}(10)$ & $13.65 \pm 4.85$ & $12.45 \pm 4.36$ & $-0.43 ;(-2.77$ to 1.92$)$ & 0.42 \\
\hline $\operatorname{lnt}(12)$ & $15.78 \pm 4.79$ & $14.02 \pm 3.59$ & & & $\operatorname{lnt}(9)$ & $13.87 \pm 3.68$ & $12.26 \pm 2.41$ & & \\
\hline \multicolumn{10}{|c|}{ Forearm non-affected } \\
\hline Con(11) & $15.61 \pm 4.17$ & $15.81 \pm 5.20$ & $-140 ;(-4.59$ to 1.78$)$ & 0.387 & Con(10) & $15.37 \pm 5.27$ & $12.66 \pm 4.00$ & $0.10 ;(-3.09$ to 3.30$)$ & 0.95 \\
\hline $\operatorname{lnt}(12)$ & $15.92 \pm 5.51$ & $14.72 \pm 5.42$ & & & $\operatorname{lnt}(9)$ & $14.68 \pm 6.23$ & $12.07 \pm 4028$ & & \\
\hline \multicolumn{10}{|c|}{ Upper arm affected } \\
\hline Con(11) & $10.66 \pm 5.57$ & $12.54 \pm 5.91$ & $-3.20 ;(-641$ to 0$)$ & 0.050 & $\operatorname{Con}(9)$ & $12.08 \pm 6.02$ & $8.92 \pm 5.19$ & $0.95 ;(-1.40$ to 3.30$)$ & 0.43 \\
\hline $\operatorname{lnt}(12)$ & $11.10 \pm 6.09$ & $9.77 \pm 3.33$ & & & $\operatorname{lnt}(9)$ & $9.63 \pm 3.53$ & $7.42 \pm 4.39$ & & \\
\hline \multicolumn{10}{|c|}{ Upper arm non-affected } \\
\hline Con(10) & $10.14 \pm 4.42$ & $12.05 \pm 6026$ & $-2.88 ;(-5.82$ to 0.06$)$ & 0.055 & Con(10) & $11.46 \pm 6.34$ & $7.97 \pm 5.18$ & $0.53 ;(-1.98$ to 3.03$)$ & 0.68 \\
\hline $\operatorname{lnt}(12)$ & $9.88 \pm 4.09$ & $8.91 \pm 3.621$ & & & $\operatorname{lnt}(9)$ & $8.17 \pm 3.54$ & $5.21 \pm 3.10$ & & \\
\hline \multicolumn{10}{|l|}{ Chest affected } \\
\hline Con(11) & $6.78 \pm 2.39$ & $5.53 \pm 3.41$ & $-0.36 ;(-2.63$ to 1.91$)$ & 0.758 & Cont(10Int(9) & $5.22 \pm 3.43$ & $5.76 \pm 1.50$ & $-0.60 ;(-2.94$ to 1.73$)$ & 0.61 \\
\hline $\operatorname{lnt}(12)$ & $6.34 \pm 2.01$ & $4.73 \pm 1.75$ & & & & $4.23 \pm 1.14$ & $4.17 \pm 1.09$ & & \\
\hline \multicolumn{10}{|c|}{ Chest non-affected } \\
\hline Con(11) & $5.59 \pm 1.84$ & $4.76 \pm 2.65$ & $-0.34 ;(-2.85$ to 2.17$)$ & $0.878^{+}$ & Con(10) & $4.70 \pm 2.79$ & $6.18 \pm 5.00$ & $-1.22 ;(-5.33$ to 2.90$)$ & 0.56 \\
\hline $\operatorname{lnt}(12)$ & $6.06 \pm 1.87$ & $4.90 \pm 1.97$ & & & $\operatorname{lnt}(9)$ & $4.98 \pm 2.23$ & $5.25 \pm 1.60$ & & \\
\hline \multicolumn{10}{|c|}{ Upper back affected } \\
\hline Con(11) & $16.17 \pm 2.39$ & $16.76 \pm 4.32$ & $0.19 ;(-3.77$ to 4.16$)$ & 0.924 & Con(10) & $16.48 \pm 4.45$ & $13.21 \pm 5.06$ & $1.10 ;(-1.51$ to 3.70$)$ & 0.41 \\
\hline $\operatorname{lnt}(12)$ & $16.06 \pm 4.18$ & $16.84 \pm 4.82$ & & & $\operatorname{lnt}(9)$ & $15.81 \pm 4.28$ & $13.63 \pm 2.930$ & & \\
\hline \multicolumn{10}{|c|}{ Upper back non-affected } \\
\hline Con(11) & $14.32 \pm 3.87$ & $15.13 \pm 5.54$ & $-1.42 ;(-4.85$ to 2.02$)$ & 0.419 & Con(10) & $15.04 \pm 5.79$ & $14.43 \pm 4.32$ & $-0.48 ;(-3.90$ to 2.95$)$ & 0.78 \\
\hline $\operatorname{lnt}(12)$ & $15.55 \pm 4.21$ & $15.05 \pm 4.86$ & & & $\operatorname{lnt}(9)$ & $14.66 \pm 5.33$ & $13.58 \pm 3.83$ & & \\
\hline
\end{tabular}

$\Delta=$ change; $\mathrm{Gp}=$ Group; $\mathrm{M}+\mathrm{SD}=$ Mean \pm Standard Deviation; $\mathrm{MD}=$ Mean Difference; $\mathrm{Cl}=$ Confidence Interval.

$\mathrm{n}=$ number.

Con = control group; Int $=$ intervention group

${ }^{+}=$non-parametic analysis; $\mathrm{b}=$ week 0 . 
Table 4 Results sensations, pain, fatigue, and limiting effect of sensations, pain, fatigue

\begin{tabular}{|c|c|c|c|c|c|c|c|c|c|}
\hline \multirow{2}{*}{$\frac{\text { VAS }}{\text { Variable Gp(n) }}$} & \multicolumn{2}{|c|}{ Group mean \pm SD b-8 } & \multicolumn{2}{|c|}{ Between group changes 0-8 } & \multirow[b]{2}{*}{ Variable Gp(n) } & \multicolumn{2}{|c|}{ Group mean \pm SD $8 b-12$} & \multicolumn{2}{|c|}{ Between group changes $8 b-12$} \\
\hline & Week $0 \mathrm{M} \pm \mathrm{SD}$ & Week $8 \mathrm{M} \pm \mathrm{SD}$ & $\Delta$ int- $\Delta$ con 0-8 MD; (95\% Cl) & $P(0-8)$ & & Week $8 b \mathrm{M} \pm \mathrm{SD}$ & Week $12 \mathrm{M} \pm \mathrm{SD}$ & $\Delta$ int- $\Delta$ con 8b-12 MD; (95\% Cl) & $P(8 b-12)$ \\
\hline \multicolumn{10}{|l|}{ Sensations } \\
\hline Con(11) & $1.97 \pm 1.89$ & $2.01 \pm 2.15$ & $-0.55 ;(02.33$ to 1.23$)$ & $0.345^{\dagger}$ & Con(10) & $2.20 \pm 2.17$ & $2.20 \pm 2.12$ & $0.30 ;(-1.21$ to 1.81$)$ & 0.698 \\
\hline $\operatorname{lnt}(12)$ & $2.39 \pm 2.12$ & $1.88 \pm 1.83$ & & & $\operatorname{lnt}(9)$ & $1.96 \pm 1.59$ & $2.26 \pm 2.29$ & & \\
\hline \multicolumn{10}{|l|}{ Pain } \\
\hline Con(11) & $1.69 \pm 2.31$ & $1.44 \pm 2.24$ & $0.06 ;(-0.74$ to 0.87$)$ & 0.878 & Con(10) & $1.57 \pm 2.31$ & $1.16 \pm 1.48$ & $0.81 ;(-0.33$ to 1.95$)$ & 0.165 \\
\hline $\operatorname{lnt}(12)$ & $0.99 \pm 1.53$ & $0.80 \pm 1.48$ & & & $\operatorname{lnt}(9)$ & $1.00 \pm 1.67$ & $1.40 \pm 1.84$ & & \\
\hline \multicolumn{10}{|l|}{ Fatigue } \\
\hline Con(11) & $1.71 \pm 2.21$ & $2.06 \pm 2.52$ & $-1.05 ;(-2.50$ to 0.41$)$ & $0.117^{\dagger}$ & Con(10) & $2.26 \pm 2.56$ & $1.57 \pm 1.54$ & $0.42 ;(-1.45$ to 2.30$)$ & $0.551^{\dagger}$ \\
\hline $\operatorname{lnt}(12)$ & $2.58 \pm 2.60$ & $1.88 \pm 2.23$ & & & $\operatorname{lnt}(9)$ & $2.37 \pm 2.50$ & $2.10 \pm 1.77$ & & \\
\hline \multicolumn{10}{|c|}{ Sensations limit activity } \\
\hline Con(11) & $1.35 \pm 2.81$ & $0.93 \pm 1.90$ & $-0.18 ;(-1.66$ to 1.30$)$ & $0.793^{\dagger}$ & Con(10) & $1.01 \pm 1.98$ & $0.8 \pm 1.70$ & $0.37 ;(-0.49$ to 1.22$)$ & 0.399 \\
\hline $\operatorname{lnt}(12)$ & $1.43 \pm 1.76$ & $0.83 \pm 0.74$ & & & $\operatorname{lnt}(9)$ & $1.20 \pm 1.54$ & $1.10 \pm 1.54$ & & \\
\hline \multicolumn{10}{|c|}{ Pain limit activity } \\
\hline Con(11) & $0.57 \pm 1.10$ & $1.31 \pm 2.39$ & $-0.99 ;(-2.06$ to 0.09$)$ & $0.362^{\dagger}$ & Con(10) & $1.42 \pm 2.49$ & $0.89 \pm 1.59$ & $0.72 ;(-0.80$ to 2.24$)$ & 0.353 \\
\hline $\operatorname{lnt}(12)$ & $0.81 \pm 1.44$ & $0.56 \pm 0.58$ & & & $\operatorname{lnt}(9)$ & $0.61 \pm 0.58$ & $0.80 \pm 0.93$ & & \\
\hline \multicolumn{10}{|c|}{ Fatigue limit activity } \\
\hline Con(11) & $0.69 \pm 1.51$ & $1.34 \pm 2.57$ & $-1.0-;(-2.44$ to 0.27$)$ & $0.315^{\dagger}$ & Con(10) & $1.46 \pm 2.67$ & $1.07 \pm 1.74$ & $0.61 ;(-0.78$ to 2.00$)$ & 0.389 \\
\hline $\operatorname{lnt}(12)$ & $1.38 \pm 1.85$ & $0.93 \pm 0.95$ & & & $\operatorname{lnt}(9)$ & $1.03 \pm 0.95$ & $1.26 \pm 1.24$ & & \\
\hline
\end{tabular}

$\Delta=$ change; $\mathrm{Gp}=$ Group; $\mathrm{M} \pm \mathrm{SD}=$ Mean \pm Standard Deviation; $\mathrm{MD}=$ Mean Difference; $\mathrm{Cl}=$ Confidence Interval; $\mathrm{n}=$ number.

Con $=$ control group; Int $=$ intervention group.

${ }^{\dagger}=$ non-parametric analysis.

$B=$ week 0 . 
Table 5 Results total Quality of Life (QOL) and QOL sub-scales

\begin{tabular}{|c|c|c|c|c|c|c|c|c|c|}
\hline \multirow{2}{*}{$\frac{\mathrm{QOL}}{\text { Variable Gp(n) }}$} & \multicolumn{2}{|c|}{ Group mean \pm SD b-8 } & \multicolumn{2}{|c|}{ Between group changes $0-8$} & \multirow[b]{2}{*}{ Variable Gp(n) } & \multicolumn{2}{|c|}{ Group mean \pm SD $8 b-12$} & \multicolumn{2}{|c|}{ Between group changes $8 b-12$} \\
\hline & Week $0 \mathrm{M} \pm \mathrm{SD}$ & Week $\mathrm{M} \pm \mathrm{SD}$ & $\Delta$ int- $\Delta$ con $0-8 \mathrm{MD} ;(95 \% \mathrm{Cl})$ & $\mathrm{P}(0-8)$ & & Week 8b M $\pm S D$ & Week $12 \mathrm{M} \pm \mathrm{SD}$ & $\Delta$ int $-\Delta$ con 8b-12 MD; $(95 \% \mathrm{Cl})$ & $p(8 b-12)$ \\
\hline \multicolumn{10}{|l|}{ Total QOL } \\
\hline Con(11) & $7.91 \pm 1.22$ & $7.45 \pm 1.44$ & $1.04 ;(-0.19$ to 2.26$)$ & $0.437^{\dagger}$ & Con(10) & $7.40 \pm 1.51$ & $7.40 \pm 1.51$ & $0.44 ;(-0.38$ to 1.27$)$ & 0.290 \\
\hline $\operatorname{lnt}(12)$ & $6.83 \pm 2.55$ & $7.42 \pm 1.24$ & & & $\operatorname{lnt}(9)$ & $7.33 \pm 0.87$ & $7.78 \pm 1.09$ & & \\
\hline \multicolumn{10}{|l|}{ Function } \\
\hline Con(11) & $1.36 \pm 0.40$ & $1.30 \pm 0.36$ & $-0.13 ;(-0.34$ to 0.09$)$ & $0.364^{\dagger}$ & Cont(10) & $1.31 \pm 0.38$ & $1.35 \pm 0.33$ & $0.13 ;(-0.07$ to 0.33$)$ & 0.210 \\
\hline $\operatorname{lnt}(12)$ & $1.48 \pm 0.48$ & $1.30 \pm 0.31$ & & & $\operatorname{lnt}(9)$ & $1.34 \pm 0.33$ & $1.51 \pm 0.14$ & & \\
\hline \multicolumn{10}{|l|}{ Appearance } \\
\hline Con(11) & $1.56 \pm 0.81$ & $1.56 \pm 0.86$ & $-0.07 ;(-0.34$ to 0.20$)$ & 0.627 & Con(10) & $1.60 \pm 0.69$ & $1.60 \pm 0.69$ & $0.10 ;(-.25$ to 0.45$)$ & 0.578 \\
\hline $\operatorname{lnt}(11)$ & $1.50 \pm 0.34$ & $1.43 \pm 0.33$ & & & $\operatorname{lnt}(9)$ & $1.42 \pm 0.37$ & $1.52 \pm 0.37$ & & \\
\hline \multicolumn{10}{|l|}{ Symptoms } \\
\hline Con(11) & $1.69 \pm 0.37$ & $1.82 \pm 0.54$ & $-0.44 ;(-0.74$ tro -0.13$)$ & $0.038^{\dagger}$ & $\operatorname{Con}(10)$ & $1.90 \pm 0.49$ & $1.73 \pm 0.47$ & $0.17 ;(-0.05$ to 0.39$)$ & 0.124 \\
\hline $\operatorname{lnt}(12)$ & $2.11 \pm 0.61$ & $1.81 \pm 0.40$ & & & $\operatorname{lnt}(9)$ & $1.91 \pm 0.38$ & $1.91 \pm 0.40$ & & \\
\hline \multicolumn{10}{|l|}{ Emotions } \\
\hline Con(11) & $1.71 \pm 0.56$ & $1.61 \pm 0.49$ & $-0.18 ;(-0.62$ to 0.26$)$ & 0.430 & Con(10) & $1.62 \pm 0.52$ & $1.60 \pm 0.56$ & $0.04 ;(-0.24$ to 0.31$)$ & 0.801 \\
\hline $\operatorname{lnt}(12)$ & $1.86 \pm 0.74$ & $1.58 \pm 0.7$ & & & $\operatorname{lnt}(9)$ & $1.44 \pm 0.45$ & $1.46 \pm 0.43$ & & \\
\hline
\end{tabular}

$\Delta=$ change; $\mathrm{Gp}=$ Group; $\mathrm{M} \pm \mathrm{SD}=$ Mean \pm Standard Deviation; $\mathrm{MD}=$ Mean Difference; $\mathrm{Cl}=$ Confidence Interval.

$\mathrm{N}=$ number.

Con = control group; Int = intervention group.

${ }^{\dagger}=$ non-parametric analysis.

$0=$ baseline. 
symptoms on the lives of women with BCRL [5] reported that ongoing symptoms continued to cause physical discomfort leading to emotional frustration and distress in spite of treatment to lessen the arm swelling. Moreover, persistent symptoms created continual challenges in the women's daily life, led to an altered self-image and constantly reminded them of the breast cancer experience. In the current trial, the degree of sensations, pain and fatigue measured separately on the VAS scale did not decrease, and yet the QOL sub-scale of symptoms, consisting of a combination of six different symptoms, improved significantly, indicating a reduction in the adverse effect of symptoms on women's QOL. A possible explanation for this combination of results could be that the actual symptoms did not reduce but the women's reaction to them did. It is possible that such a finding may be attributable to the mindful awareness component of yoga, whereby practitioners learn to witness physical and mental discomfort without engaging with that discomfort. A study that used yoga as an intervention for women undergoing radiotherapy for breast cancer reported a positive correlation between a higher number of intrusive thoughts and benefit finding from the cancer experience [35]. The researchers suggested this may be a result of mindful awareness, in that the intrusive thoughts actually increased, but a negative reaction to the thoughts did not occur. Symptom management is integral to lymphoedema treatment [5,36]. Ridner and colleagues [6] postulated that current lymphoedema treatment may not deal adequately with the symptom cluster experienced by women with BCRL and so complementary therapies may provide other management options to reduce the adverse effects commonly reported. The results of the current trial support this postulation.

As other QOL sub-scales did not improve in the current trial, it may be that the reduction in symptoms precedes the improvement in other QOL domains. Comparison with other trials for women with BCRL is difficult, as different QOL tools were used that did not include a sub-scale of lymphoedema symptoms. Only one yoga trial could be found that reported on symptoms and QOL ratings. A 12-week yoga intervention for women during and after breast cancer treatment, using the Functional Assessment of Cancer Therapy QOL tool, found improvements in total QOL and in the social and emotional QOL sub-scales only in the women not experiencing symptoms from chemotherapy [37]. Although the symptoms experienced by women from chemotherapy are different to those from BCRL, it may indicate that symptom amelioration precedes improvement in other QOL domains. It would appear that a holistic yoga intervention may be effective in improving symptoms; however, a longer intervention with larger numbers is needed to further test the strength of this hypothesis or whether yoga leads to a decrease in the other QOL domains.

Physical therapy, as an early intervention, has been recommended for the prevention or reduction of the morbidity associated with the effects of breast cancer treatment and lymphoedema [9]. The yoga intervention was based on gentle and modified physical movements. The benefits gained may indicate that yoga can offer another option as an early physical therapy. It may also provide an intermediary to more strenuous forms of exercise and counteract the fear that some women have in resuming exercise $[11,38]$. Current best-practice recommends early intervention to prevent lymphoedema becoming worse [39]. That the generally lower levels of lymphoedema did not increase in this trial along with the reduction in tissue induration of the affected upper arm, and improvement in the symptoms sub-scale of QOL may offer preliminary support that yoga may be a helpful intervention post-surgery.

This trial had several limitations. Women in the current trial had been clinically diagnosed with stage one lymphoedema according to the definition from the International Society of Lymphology [3], using standardised testing and equipment and based on guidelines of the Australasian Lymphology Association [27]. However, many of the baseline scores for BIS (L-dex >10) and volume of arm lymphoedema $(>200 \mathrm{ml}$ ) were low and women with higher levels of BCRL may not have experienced similar results. Hence a recommendation for future studies would be to make an L-dex of $>10$ or volume of arm lymphoedema $(>200 \mathrm{ml})$ an additional inclusion criteria and that this measure be confirmed by the research team. Furthermore, fluctuation of levels $[7,40]$ may have occurred in the trial. However, it was considered the control group would account for any factors other than the intervention which might be responsible for changes in the outcome variables. As there were no significant within group differences in the control group for any measure of lymphoedema, fluctuation of levels seems an unlikely explanation for our results. There were large, albeit non-significant, mean differences between treatment groups in several variables at baseline. When baseline results were included as a covariate for comparison of the two groups for the primary outcome variables and those for which a statistically significant result was observed, this did not affect the significance of the result for the tested variable. As a result, it is unlikely that these imbalances affected changes occurring in the variables during the intervention period. In addition, sample size was small, which was partially due to all participants starting at the same time and yoga classes running as a group meaning that additional participants were unable to be recruited to make up for withdrawals and this may have limited some findings. A post-hoc power calculation has revealed that using this 
study as a pilot for a future study, 179 participants would be required per group aiming to detect a $12 \%$ difference in change in lymphoedema between the control and the intervention groups based on the observed standard deviation of the between group change as the standard deviation of the changes was greater than expected. A longer intervention may have increased the degree of change or the duration of the beneficial change. Further, the higher BMI of the yoga compared to the control group at baseline may have confounded the results, but due to the small sample size it was thought that covariate analysis using BMI would not produce substantial results. As BMI did not change over the course of the intervention, it was unlikely that it affected results. The yoga intervention was based on Satyananda Yoga ${ }^{\circ}$ using specific practices thought to reduce the effects of lymphoedema and thus the findings may not be generalised to other styles of yoga.

\section{Conclusion}

The outcomes of this small pilot trial provide preliminary evidence that an 8-week Satyananda Yoga intervention, based on guidelines for exercise and lymphatic drainage did not exacerbate lymphoedema measured by arm volume and extra-cellular fluid and improved tissue induration of the affected upper arm and the QOL sub-scale of symptoms. However, the fact that these improvements were not maintained at the 1-month follow-up when arm volume of lymphoedema also increased suggests that the yoga needs to be ongoing. Future yoga trials of longer duration, higher levels of lymphoedema and higher participant numbers are warranted to better elucidate these potential benefits with the recommendation that future trials make an L-dex of $>10$ or volume of arm lymphoedema $(>200 \mathrm{ml})$ an additional inclusion criteria confirmed by the research team.

\section{Abbreviations}

BCRL: Breast cancer-related lymphoedema; QOL: Quality of life.

\section{Competing interests}

The authors declare that they have no competing interests.

\section{Authors' contributions}

AL conceived the trial and with TB and ADW were responsible for the design of this trial and the construction of the measurement protocol. $\mathrm{AL}$ conducted the yoga intervention. NP was responsible for the design of the lymphoedema methodology. MAI assisted in design of the trial and advice for the yoga intervention. AL and ADW conducted the statistical analysis. AL and ADW drafted and TB, NP, MAl helped draft the manuscript. All authors read and approved the final manuscript.

\section{Authors' information}

$\mathrm{AL}$ is a yoga researcher and trains yoga teachers in yoga therapy. TB is Director of Rural Health, University of Tasmania. ADW is a senior lecturer in Clinical Exercise Science, University of Tasmania. NP is Director of the lymphoedema clinic at Flinders University. MAl is Director of physical movement and yoga researcher at University of South Australia.

\section{Acknowledgements}

This study was supported by grants from the Swan Research Institute (SRI) and the Faculty of Health Sciences Seed Funding, UTAS. Equipment was provided by Flinders University and University of Tasmania. The Women's Health Centre, Hobart and the Launceston Community Health Centre, Kings Meadows provided venue for conducting the yoga intervention and testing. We acknowledge the voluntary provision of professional services in testing by Marlene Kalis, Christine Lambrechts, Michele Smith, Belinda Mann, Kara Spaulding, Lara Matuszek and Megan Reid and the professional assistance of Chris Dale and Professor David McNeil. We are indebted to the women of Tasmania who volunteered for this trial.

\section{Registration}

The Australian New Zealand Clinical Trials Registry ACTRN12611000202965.

\section{Author details}

${ }^{1}$ Centre for Rural Health, University of Tasmania, Launceston, Australia. ${ }^{2}$ School of Medicine, Flinders University, Adelaide, Australia. ${ }^{3}$ School of Health Sciences, University of South Australia, Adelaide, Australia. ${ }^{4}$ School of Health Sciences, University of Tasmania, Launceston, Australia.

Received: 29 July 2013 Accepted: 23 June 2014

Published: 1 July 2014

\section{References}

1. Australian Institute of Health and Welfare, National Breast and Ovarian Cancer Centre: Breast Cancer in Australia: An Overview, 2009. Cancer Series no. 50, Cat. No. CAN 46. Canberra, ACT, Australia: AlHW; 2009.

2. National Breast and Ovarian Cancer Centre: Lymphoedema-What you Need to Know. Surry Hills, NSW, Australia: NBOCC; 2008.

3. Framework L: Best Practice for the Management of Lymphoedema. MEP Ltd: London, United Kingdom; 2006.

4. Brennan MJ: Lymphoedema following the surgical treatment of breast cancer: a review of pathophysiology and treatment. J Pain Symptom Manage 1992, 7:110-116.

5. Fu MR, Rosedale M: Breast cancer survivors' experiences of lymphedemarelated symptoms. J Pain Symptom Manage 2009, 38:849-859.

6. Ridner SH: Quality of life and a symptom cluster associated with breast cancer treatment-related lymphedema. Support Care Cancer 2005, 13:904-911.

7. Hayes SC, Janda M, Cornish B, Battistutta D, Newman B: Lymphedema following breast cancer: incidence, risk factors, and effect on upper body function. J Clinic Oncol 2008, 26:3536-3542.

8. Chachaj A, Malyszczak K, Pyszel K, Lukas J, Tarkowski R, Pudelko M, Andrzejak R, Szuba A: Physical and psychological impairments of women with upper limb lymphedema following breast cancer treatment. Psychooncology 2010, 19:299-305.

9. Schmitz KH: Balancing lymphedema risk: exercise versus deconditioning for breast cancer survivors. Exerc Sports Sci Rev 2009, 38:17-24.

10. Brown JC, Troxel AB, Schmitz KH: Safety of weightlifting among women with or at risk for breast cancer-related lymphedema: musculoskeletal injuries and health care use in a weightlifting rehabilitation trial. Oncologist 2012, 17:112-118.

11. Hayes SC, Reul-Hirche HM, Turner J: Exercise and secondary lymphedema: safety, potential benefits, and research-related issues. Med Sci Sports Exerc 2009, 41:483-489.

12. McKenzie DC, Kalda AL: Effect of upper extremity exercise on secondary lymphedema in breast cancer patients: a pilot study. J Clinic Oncol 2003, 21:463-466.

13. Schmitz KH, Ahmed RL, Troxel AB, Cheville A, Smith R, Lewis-Grant L, Bryan CJ, Williams-Smith $C T$, Green QP: Weight-lifting in women with breast cancer-related lymphedema. New Eng J Med 2009, 361:664-673.

14. Moseley AL, Piller NB, Carati CJ: The effect of gentle arm exercise and deep breathing on secondary arm lymphedema. Lymphology 2005 , 38:136-145

15. Tidhar D, Katz-Leurer M: Aqua lymphatic therapy in women who suffer from breast cancer treatment-related lymphedema: a randomized controlled study. Support Care Cancer 2010, 18:383-392.

16. McClure MK, McClure RJ, Day R, Brufsky AM: Randomised controlled trial of the breast cancer recovery program for women with breast cancer-related lymphedema. Am J Occup Ther 2010, 64:59-72. 
17. Iyengar B: Light on Yoga. Harper Collins: London, United Kingdom; 2001.

18. Narahari S, Ryan TJ, Bose KS, Prasanna KS, Aggithaya GM: Integrating modern dermatology and Ayurveda in the treatment of vitiligo and lymphedema in India. Int I Dermatol 2011, 50:310-334.

19. Cramer H, Lange S, Klose P, Paul A, Dobos G: Yoga for breast cancer patients and survivors: a systematic review and meta-analysis. BMC Cancer 2012, 12:412.

20. Finnane A, Liu Y, Battistutta D, Janda M, Hayes SC: Lymphedema after breast or gynecological cancer: use and effectiveness of mainstream and complementary therapies. J Altern Complement Med 2011, 17:867-869.

21. Loudon A, Barnett T, Piller N, Immink MA, Visentin D, Williams AD: The effect of yoga on women with secondary arm lymphoedema from breast cancer treatment. BMC Complement Altern Med 2012, 12:66.

22. Johansson K, Tibe K, Weibull A, Newton RU: Low intensity resistance exercise for breast cancer patients with arm lymphedema with or without compression sleeves. Lymphology 2005, 38:167-189.

23. Saraswati $S$ (Ed): Asana, Pranayama, Mudra, Bandha. Munger, India: Bihar School of Yoga; 1996.

24. Loudon A, Barnett T, Piller N, Williams A, Immink MA: Using yoga in breast cancer-related lymphoedema. J Lymphoedema 2012, 7:27-36.

25. Piller NB: To measure or not to measure? What and when is the question. J Lymphoedema 2007, 2:39-45.

26. Rockson SG: Bioimpedance analysis in the assessment of lymphoedema diagnosis and management. J Lymphoedema 2007, 2:44-48.

27. Lymphoedema management. [http://www.lymphoedema.org.au/ALA/ Lymphoedema/Lymphoedema_Management/ALA/Lymphodema/ Lymphoedema_Management.aspx?hkey=74ef07e8-c742-461e-869aac5e5ad9c53c]

28. Stanton AWB, Badger C, Sitzia J: Non-invasive assessment of the lymphedematous limb. Lymphology 2000, 33:122-135.

29. Czerniec SA, Ward LC, Refshauge KM, Beith JM, Lee M-J, York S, Kilbreath SL: Assessment of breast cancer-related arm lymphedema-comparison of physical measurement methods and self-report. Cancer Invest 2010, 28:54-62.

30. Clodius $L$, Deak L, Piller NB: A new instrument for the evaluation of tissue tonicity in lymphoedema. Lymphology 1976, 9:1-5.

31. Harms-Ringdahl K, Carlsson AM, Ekholm J, Raustorp A, Svensson T, Toresson HG: Pain assessment with different intensity scales in response to loading of joint structures. Pain 1986, 27:401-411.

32. Keeley V, Crooks S, Locke J, Veigas D, Riches K, Hilliam R: A quality of life measure for limb lymphoedema (LYMQOL). J Lymphoedema 2010, 5:26-37.

33. Evans S, Sternlieb B, Tsao JCl, Zeltzer LK: Using the biopsychosocial model to understand the health benefits of yoga. J Complement Integr Med 2009, 6:1-22.

34. Ridner SH: The psycho-social impact of lymphedema. Lymphat Res Biol 2009, 7:109-112

35. Chandwani KD, Thornton B, Perkins GH, Banu A, Raghuram NV, Nagendra $H R$, Wei $Q$, Cohen L: Yoga improves quality of life and benefit finding in women undergoing radiotherapy for breast cancer. I Soc Integr Oncol 2010, 8:43-55.

36. Dawes DJ, Meterissian S, Goldberg M, Mayo NE: Impact of lymphoedema on arm function and health-related quality of life in women following breast cancer surgery. J Rehabil Med 2008, 40:651-658.

37. Moadel AB, Shah C, Wylie-Rosett J, Harris MS, Patel SR, Hall CB, Sparano JA: Randomised controlled study of yoga among a multiethnic sample of breast cancer patients: effects on quality of life. J Clinic Oncol 2007, 25:4387-4395.

38. Lee TS, Kilbreath SL, Sullivan G, Refshauge KM, Beith JM, Harris LM: Factors that affect intention to avoid strenuous arm activity after breast cancer surgery. Oncol Nurs Forum 2009, 36:454-462.

39. Hayes SC, Johansson K, Stout NL, Prosnitz R, Armer JM, Gabram S, Schmitz $\mathrm{KH}$ : Upper-body morbidity after breast cancer: Incidence and evidence for evaluation, prevention, and management within a prospective surveillance model of care. Cancer 2012, 118:2237-2249.

40. Kilbreath SL, Lee MJ, Refshauge KM, Beith JM, Ward LC, Simpson JM, Black D: Transient swelling versus lymphoedema in the first year following surgery for breast cancer. Support Care Cancer 2013, 21:2207-2215.

doi:10.1186/1472-6882-14-214

Cite this article as: Loudon et al:: Yoga management of breast cancer-related lymphoedema: a randomised controlled pilot-trial. BMC Complementary and Alternative Medicine 2014 14:214.

\section{Submit your next manuscript to BioMed Central and take full advantage of:}

- Convenient online submission

- Thorough peer review

- No space constraints or color figure charges

- Immediate publication on acceptance

- Inclusion in PubMed, CAS, Scopus and Google Scholar

- Research which is freely available for redistribution 